\title{
Regulação e accountability na (re)configuração das políticas para a educação
}

\section{Regulation and accountability in (re)configuration of policies for education Regulación y responsabilidad en la (re)configuración de políticas para la educación}

\author{
ANA LÚCIA FELIX SANTOS \\ http://orcid.org/0000-0002-1040-2156 \\ Universidade Federal de Pernambuco \\ Programa de Pós-graduação em Educação \\ Faculdade de Educação \\ Pernambuco, PE, Brasil \\ EMÍLIA VILARINHO \\ http://orcid.org/0000-0001-5760-3716 \\ Universidade do Minho \\ Centro de Investigação em Educação \\ Instituto de Educação \\ Braga, Portugal
}

\begin{abstract}
Resumo: Este estudo aborda a accountability enquanto elemento da política educacional. Entende que a accountability educacional consiste em ações de política que envolvem a interação entre avaliação, prestação de contas e responsabilização. Considera que as políticas de avaliação educacional, da forma como vêm sendo instituídos no nosso país, se apresentam como medidas de regulação da educação. Com base em pesquisa bibliográfica, problematiza o conceito de accountability e revela que ele vem sendo estudado de diferentes formas. Há textos puramente analíticos e há textos analíticos e propositivos. Nesses últimos, é possível encontrar uma perspectiva neoliberal de cunho gerencialista e uma perspectiva crítica.
\end{abstract}

Palavras-chave: Avaliação educacional. Accountability. Regulação da educação.

\begin{abstract}
This study addresses accountability as an element of educational policy. It understands that educational accountability consists of policy actions that involve the interaction between evaluation, accountability, and responsibility. It considers that educational evaluation policies, as they have been instituted in our country, present themselves as measures to regulate education. Based on literature research, it problematizes the concept of accountability and reveals that it has been studied in different ways. There are purely analytical texts and there are analytical and propositional texts. In this latter, it is possible to find a neo-liberal managementbased perspective and a critical one.
\end{abstract}

Keywords: Education evaluation. Accountability. Education regulation. 
Resumen: Este estudio adopta la accountabylity como elemento de la politica educativa en su tema de investigación. Entiende que la accountabylity educativa consiste en acciones de política que involucran la interacción entre evaluación, la accountabylity y responsabilidad. Considera que las políticas de evaluación educativa, como se han instituido en nuestro país, se presentan como medidas de la regulación de la educación pública. Apoyado en la investigación bibliográfica, problematiza el concepto de la accountabilityy revela que ha sido estudiado de diferentes maneras. Hay textos puramente analiticos, y hay textos analíticos y proposicionales. En estos últimos, es posible encontrar textos con proposición en una perspectiva neoliberal de naturaleza gerencial y en una perspectiva crítica.

Palabras clave: Evaluación de la educación; la accountability; regulación de la educación.

\section{INTRODUÇÃO}

Este estudo adota como tema de pesquisa a accountability educacional enquanto elemento da política que vem tomando corpo nos últimos anos no Brasil e em outros países. Tomando como exemplo da força dessas ações, vemos que estados brasileiros vêm construindo e adotando políticas específicas para avaliação dos seus sistemas de ensino com fortes componentes de accountability. Entendemos neste estudo que a accountability educacional consiste em ações de política que envolvem a interação entre os pilares da avaliação, prestação de contas e responsabilização (AFONSO, 2012). Por outra parte, entendemos que tais pilares não se expressam de uma só forma, assim, há uma diversidade de ações envolvendo diferentes nuances dos pilares citados acima, que se expressam em diferentes sistemas de avaliação da educação básica nos estados brasileiros.

Aqui no nosso país temos o Sistema de Avaliação da Educação Básica (Saeb), um sistema que tem se fortalecido ano a ano ao conseguir sistematizar dados relativos à educação brasileira, especialmente em sua articulação com o Índice de Desenvolvimento da Educação Básica (Ideb). Mesmo com a reorientação do Saeb, que desde 2005 passou a aplicar a Prova Brasil de forma censitária, os estados brasileiros continuaram a desenvolver seus sistemas próprios de avaliação, partindo principalmente da justificativa de que os dados do sistema nacional são descontextualizados e que só são divulgados de dois em dois anos, o que limita a formulação de políticas para atender às especificidades escolares (MACHADO et al., 2015). 
De um lado, os estados passam a questionar-se acerca da validade da manutenção de sistemas próprios, com seus altos custos e complexidade logística, para realizar a mesma função que o governo federal já realiza. De outro, se estabelece uma frequência muito alta de aplicação de provas, o que inviabiliza, até mesmo, o tempo necessário para que seus resultados sejam absorvidos, analisados e transformados em ações por parte das redes de ensino. (SOUZA; OLIVEIRA, 2010, p. 812).

A despeito dessas observações e questionamentos, pesquisas apontam o avanço dessas políticas de avaliação educacional e o consequente uso de avaliações externas acompanhado de fortes componentes de accountability. Oliveira (2019, p. 28) nos informa que "tomando como referência os vinte e seis estados federados, computa-se que vinte deles, mais o Distrito Federal, possuem sistemas próprios de avaliação da educação básica no ano de 2018”. Consideramos que, da forma como vêm sendo instituídos no nosso país, tais políticas se apresentam como medidas de regulação da educação pública e se vinculam a estratégias de responsabilização por resultados, colocando professores e gestores escolares como centro da responsabilidade educacional, através do uso de indicadores e de metas de atendimento para as escolas, muitas vezes seguido de bonificação por desempenho.

Partimos do pressuposto de que esse processo de regulação consiste nas mudanças que os estados nacionais vêm adotando sobre seus modos de governar, que, de forma dialética, são imputados pelo fortalecimento do neoliberalismo e das formas gerencialistas de administração da coisa pública. Nesse movimento, a accountability vai sendo instaurada aos moldes do mercado financeiro, e sua constituição de agente disciplinante vale para todos os atores sociais (em comparação com atores empresariais): "todos devem se submeter ao princípio da accountability, isto é, à necessidade de 'prestar contas' e ser avaliado em função de resultados obtidos” (DARDOT; LAVAL, 2016, p. 201).

É possível observar que os sistemas estaduais de avaliação da educação, em sua maioria, tomam como modelo o Saeb. No entanto, nesse âmbito administrativo, as estratégias de política vêm agregando outros elementos aos processos, como o estabelecimento de metas vinculadas a algum indicador de desempenho e o pagamento de bonificação aos professores e gestores escolares. Silva (2016, p. 510), afirmando essa tendência, nos informa que "as iniciativas estaduais e municipais de avaliação externa e de pagamento de professores por desempenho estão se expandindo no país, fundadas nos princípios da competitividade, da meritocracia e da responsabilização". 
A responsabilização, entendida aqui como um dos elementos da accountability educacional, aparece como fator preponderante nessas políticas, isso porque essas últimas "tornam públicas as informações sobre o trabalho das escolas e consideram-se os gestores e outros membros da equipe escolar como coresponsáveis pelo nível de desempenho alcançado pela instituição" (BROOKE, 2006, p. 378).

Dardot e Laval (2016) inserem esse debate no âmbito da emergência do neoliberalismo e afirmam que o processo de responsabilização vai além da função de tornar os indivíduos responsáveis, intimando-os a responder por seu comportamento a partir de escalas de medida definidas pela gestão. As propostas de avaliação dos sistemas educacionais advogam uma responsabilização com esse sentido.

\begin{abstract}
A “avaliação" tornou-se o primeiro meio de orientar a conduta pelo estímulo ao "bom desempenho" individual. Ela pode ser definida como uma relação de poder exercida por superiores hierárquicos encarregados da expertise dos resultados, uma relação cujo efeito é uma subjetivação contábil dos avaliados. Uma vez que o sujeito aceita ser julgado com base nessas avaliações e sofrer as consequências, ele se torna constantemente avaliável, isto é, um sujeito que sabe que depende de um avaliador e das ferramentas empregadas por ele, sobretudo porque ele mesmo foi educado para reconhecer de antemão a competência do avaliador e a validade das ferramentas. (DARDOT; LAVAL, 2016, p. 351)
\end{abstract}

É a partir desse cenário que o presente estudo se volta para a compreender melhor a categoria accountability e seu vínculo com políticas de avaliação educacional. A necessidade de um estudo mais estruturado que envolva esse tema é apontada por Afonso (2012), que afirma haver um fetiche em torno dessas propostas, apresentadas como resposta para superação dos problemas educacionais. Desse modo, levantamos a seguinte questão: Que significados podem ser apreendidos da palavra accountability? Nossa intenção consiste em discutir essa temática, a partir de uma incursão teórica que problematize a relação entre regulação e accountability educacional tomada no sentido da interação entre avaliação, responsabilização e prestação de contas. Buscamos trabalhar com uma pequena parte desse rico debate que envolve a accountability educacional e sua expressão nas políticas de educação na atualidade, conforme abordaremos na seção 3 desse artigo. Antes, é necessário debater a relação entre regulação, responsabilização e accountability, o que faremos a seguir. 


\section{REGULAÇÃO DA EDUCAÇÃO, RESPONSABILIZAÇÃO E ACCOUNTABILITY}

Se, por um lado, o uso das avaliações se baseia na ideia de que a qualidade da educação pode ser medida pela aplicação de testes padronizados e sistemáticos, por outro, o uso de práticas de accountability (que envolvem a avaliação) vai sendo difundido sob o discurso de que é a correção para todos os males da educação. Perboni (2016) observa isso ao analisar os partidos políticos, os sistemas de avaliação e as políticas que envolvem práticas de accountability, demonstrando que não há relação direta entre os mesmos. Ou seja, o uso do termo e das políticas de accountability está na moda, e isso independe do partido político que está no poder, mas parece afinar-se com diferentes modelos liberais e neoliberais de governar.

A referência frequente à necessidade de implementação de certas formas de accountability transformou-se numa panacéia (ou mesmo num fetiche) pelo facto de a avaliação, a prestação de contas e a responsabilização serem, supostamente, capazes de, por si sós, satisfazer as expectativas de grupos e setores sociais aparentemente desejosos de resolver os défices e proble

Políticas de accountability educacional que envolvem a interação entre avaliação, prestação de contas e responsabilização ${ }^{1}$ são entendidas neste trabalho como estratégias de regulação e controle da educação, que podem ser estudadas de diferentes modos ou sob diferentes perspectivas. Neste trabalho, optamos por entendê-las como um sistema complexo que se presta à regulação da educação e acaba por induzir outras políticas, como (des)valorização profissional e docente; políticas curriculares; políticas de avaliação educacional; e políticas que carregam no seu interior um determinado modelo de gestão escolar e de prática pedagógica que acaba por cercear a autonomia pedagógica e de gestão dos envolvidos com os processos educativos no interior das escolas. Ao utilizar procedimentos de geração de dados, de divulgação de resultados, de estabelecimento de padrões ou metas, dentre outras estratégias que incidem sobre as escolas, sobre os sistemas de ensino, sobre os profissionais da educação e sobre os estudantes, tais políticas acabam por ter um caráter sistêmico. Ao focar nos resultados dos estudantes (a

1 Definir que termo utilizar para nomear o objeto de nosso estudo não foi tarefa fácil. Na língua portuguesa não há uma definição ou tradução da palavra accountability, e na nossa literatura diferentes autores utilizam distintas conceituações ou diferentes entendimentos sobre o assunto. Vejamos alguns exemplos de uso de termos utilizados para se referir à relação entre política de avaliação e accountability educacional: Política de controle por resultados (MAROY; VOISIN, 2013); sistemas baseados na responsabilidade pelos resultados (LABEI, 2006); mecanismos de accountability (responsabilização) (ADRIÃO; GARCIA, 2008); política de accountability centrada na responsabilização (SILVA; SILVA, 2014); políticas de avaliação com objetivos de accountability (SCHNEIDER, 2017); políticas de accountability, vinculadas à bonificação de profissionais da educação (BROOKE, 2013). 
partir da aplicação de testes padronizados), as políticas de accountability educacional promovem um controle e uma regulação centrados no produto e não nos processos, o que revela contornos de um padrão de política pública que se afina com as formas de regulação estatal neoliberal em voga atualmente.

Com essa característica, a avaliação em larga escala (assim como os outros elementos da accountability) tanto se constitui como um exercício de poder, quanto pode acionar mecanismos de regulação capazes de adentrar o contexto escolar de uma forma sutil, como se compusesse a dinâmica interna da escola, influenciando processos, mas com foco nos resultados (NOGUEIRA, 2015, p. 31).

Nesse movimento, é importante discernir sobre o conceito de regulação e sobre os usos desse termo ao se tratar das políticas educacionais atuais. Boyer (1990), considerando que esse termo é ao mesmo tempo sedutor e generalizante, nos diz que ele acabou por ser tratado com diferentes sentidos e que promoveu uma multiplicação de referências e certas confusões. A regulação pode ser entendida como conceito transversal à teoria dos sistemas; intervenção ativa e consciente do Estado ou de outras organizações coletivas; além de conjunção dos mecanismos que promovem a reprodução geral, tendo em vista as estruturas econômicas e as formas sociais vigentes. Esse autor adota a última concepção como a que ele explora, pois se trata do "ponto central comum às diversas correntes que reivindicam a regulação" (BOYER, 1990, p. 46). E define o que seja um modo de regulação:

Consequentemente, qualificaremos como modo de regulação todo um conjunto dos procedimentos e de comportamentos, individuais ou coletivos, com a tripla propriedade de: reproduzir as relacooos sociais fundamentais através da conjunção de formas institucionais historicamente determinadas; sustentar $e$ pilotar o regime de acumulação em vigor; garantir a compatibilidade de um conjunto de decisões descentralizadas, sem que seja necessária a interiorização dos princípios de ajustamento do sistema como um todo por parte dos atores econômicos (BOYER, 1990, p. 80, grifos do autor).

Mesmo entendendo que o ato de regular é ação legítima e inerente ao Estado por sua própria natureza, temos acompanhado historicamente uma redefinição dessa ação, com a finalidade de atender a mudanças nos modos de regulação estatal, ou seja, na estrutura e na forma de governar. Azevedo e Gomes (2009), problematizam a centralidade que o conceito de regulação estatal apresentam na atualidade, conceito que aparece atrelado às novas formas de atuação estatal, que buscam maior controle sobre a vida social e econômica através da implantação de determinadas políticas públicas. No caso da educação, isso é visível com a implantação de políticas de avaliação externa. 
O sistema de educação ou a educação escolar é uma componente central do modo de regulação em qualquer sociedade diferenciada e desigual. A montagem e a existência de instituições educacionais diferentes, as práticas de avaliação da aprendizagem e de avaliação das instituições de ensino da educação básica e superior, as formas de regulação intra-sistêmica que definem formas de comportamentos, títulos e status não apenas são condicionadas pela estrutura social historicamente engendrada, como se relacionam com o mundo do trabalho, o qual tem como fundamento um sistema de recompensas pecuniária e simbólica. Assim, pode-se compreender por que a educação é parte importante do modo de regulação e dele não pode se desvencilhar. Talvez seja a educação, como processo social e escolar, o locus principal do modo de regulação, porque é ela mesma constituinte das formas e processos da reprodução social. (AZEVEDO; GOMES, 2009, p. 102)

Como anunciamos no início deste trabalho, no Brasil estados subnacionais adotam amplamente essas estratégias, conforme é possível destacar nos estudos de Oliveira (2019), por exemplo.

O que se percebe nesse mecanismo de regulação é uma vinculação direta com a melhoria da qualidade da educação, no entanto a perspectiva de qualidade anunciado pelo discurso da avaliação de sistemas via testes estandardizados buscam enfatizar a eficácia dos resultados acadêmicos dos estudantes e corroboram com as exigências de mercado e defendem a capacidade competitiva da sociedade em geral. (LINDOSO; SANTOS, 2019, p. 12).

Nesse discurso, argumenta-se a favor de que é necessário definir metas de desempenho dos estudantes e das escolas e, posteriormente, aplicar exames aos estudantes para analisar os hiatos de qualidade entre o que se propôs enquanto meta e o que foi possível alcançar enquanto desempenho estudantil.

Em meio a essas ações que disseminam um referencial normativo articulado ao processo de acumulação capitalista, a centralidade e a consolidação de mecanismos de avaliação em larga escala adotadas como estratégias de ação e regulação governamental são tônicas para empreender mudanças no setor educacional. Tal centralidade associa a avaliação à qualidade da educação e tem levado diversos pesquisadores a afirmar que estamos vivenciando concepções estatais denominadas de estado avaliador e estado articulador. Quando se trata do campo educacional, o Estado avaliador expressa-se principalmente pelas pressões que o poder central exerce sobre as escolas, através de exames nacionais ou de estratégias de presença mais frequente de agentes advindos da inspeção do poder central.

Assim, o estado se torna avaliador e não se contenta mais em verificar se as 
regras foram respeitadas ou os orçamentos bem ajustados às necessidades; ele multiplica os instrumentos para a avaliação dos resultados (que, aliás, já existiam em alguns casos) para usá-los como ferramentas de gestão dessas políticas e não exclusivamente como ferramentas pedagógicas a serviço de uma regulamentação local de tipo pedagógico pelos profissionais (MONS, 2009). As avaliações externas estão sendo cada vez mais utilizadas para "regular" e orientar o comportamento dos atores intermediários e locais. Esse aumento da avaliação caminha junto com uma maior explicitação dos padrões curriculares e de desempenho que devem (ao menos teoricamente) sustentar as avaliações. (MAROY; VOISIN, 2013, p. 895).

Esse é um dos movimentos que marcam as políticas de regulação com base na accountability, atualmente vinculada à noção de Estado avaliador e regulador, e que envolvem os mecanismos de controle da atividade pedagógica via estabelecimento de padrões e sanções, ou seja, mesmo com ações que controlam o processo, o que importa na realidade é o resultado quantitativo.

\section{POLÍTICAS DE EDUCAÇÃO E ACCOUNTABILITY - DIFERENTES PERSPECTIVAS}

$\mathrm{Na}$ literatura encontramos diferentes formas de lidar com o termo accountability. No Brasil, há uma tendência, que vem desvanecendo aos poucos, de considerar accountability como sinônimo de responsabilização. Como é possível apreender em Furtado (2015, p. 19), "vivemos, agora, o momento da responsabilização em educação (accountability)"; ou em Cunha (2015, p. 7): “O termo accountability não possui uma tradução exata na Língua Portuguesa, dessa forma, estabeleceu-se um consenso sobre o termo como responsabilização". Esse mesmo autor continua sua explanação e nos diz que "na verdade, o conceito de accountability é mais amplo e envolve outros parâmetros para além da responsabilização". É nesse movimento de buscar explorar diferentes perspectivas que abordam a accountability educacional que traçamos algumas considerações com base em autores distintos.

Há textos puramente analíticos e há textos analíticos e propositivos. Nesses últimos, é possível encontrar textos numa perspectiva neoliberal e textos numa perspectiva crítica. Há, na verdade, uma grande variedade de autores trabalhando com essa temática, analisando, discutindo, criticando ou defendendo.

Entre as diversas possibilidades aqui, optamos por trazer elementos do trabalho de Maroy e Voisin (2013), que analisam de forma crítica a evolução desse tipo de política, intitulando-o políticas de controle por resultados; num segundo momento, apresentamos as contribuições da Latin American Basic Education Initiative (LABEI, 2006) e McMeekin (2006), ambos os textos extraídos de uma produção 
que defende fortemente o que chamam de sistema de prestação de contas, com uma perspectiva propositiva neoliberal; e, por fim, trazemos estudos de Afonso (2009; 2012), que ao analisar o termo apresenta uma proposição crítica e reflexiva.

Como exposto, Maroy e Voisin (2013) criaram a expressão políticas de controle por resultados. Buscando clarificar o que são tais políticas, os autores nos informam sua constituição em quatro dimensões: a primeira define a escola como um "sistema de produção" com as metas das políticas dirigidas aos indivíduos, numa perspectiva liberal, expressas em números objetivos e com foco na quantidade (com a construção de padrões de referência); a segunda dimensão relaciona-se com a anterior, é o chamado "governar por números"; a terceira envolve uma centralidade nos instrumentos de avaliação; e por fim, há o desenvolvimento de ferramentas públicas a fim de organizar as consequências necessárias para "motivar" os envolvidos nesse tipo de política.

Tomando essas características e analisando experiências internacionais, os autores vão identificar o que eles chamam de accountability dura ou hard (cujas sanções são mais pesadas) e a accountability suave ou reflexiva, cujo processo de avaliação leva a sanções leves. A primeira prevê o estabelecimento padronizado de normas curriculares e de desempenho padronizados, alinhadas às avaliações e com práticas profissionais baseadas nessas normas, além de sanções significativas para os que não atingem os objetivos. Tais sanções podem até envolver fechamento de escolas e demissões dos profissionais das escolas. Já “[os] sistemas de accountability 'suave' ou 'reflexiva' baseiam-se na suposição de engajamento e de reflexividade dos atores e num modelo de obrigação de resultados que façam preferencialmente apelo à autoavaliação e não à sanção externa" (MAROY; VOISIN, 2013, p. 886). De todo modo, é possível dizer que esses sistemas incorporam os seguintes elementos: padrões de referência, ferramentas de avaliação e mecanismos de prestação de contas.

As políticas de accountability apresentam, portanto, na realidade uma grande diversidade associada à forma como os diferentes instrumentos estão ligados, ou mesmo alinhados em várias configurações articuladas por padrões, ferramentas de avaliação, relação de prestação de contas (por exemplo, entre, por um lado, as "autoridades administrativas" e, por outro, os estabelecimentos e seus atores: professores, pais, diretores, alunos...). Em outras palavras, as ferramentas utilizadas e os mecanismos que as unem umas às outras constituem elementos de análise chave para compreender os significados e as orientações sociopolíticas diversas dos sistemas de accountability que eles operacionalizam. (MAROY; VOISIN, 2013, p. 886) 
Buscando realizar uma análise da evolução desses tipos de política, os autores recorrem a duas tipologias, uma delas baseada nos princípios normativos subjacentes à relação de prestação de contas e suas formas de organização apresentada por Kogan, e outra baseada naquilo que contribui para a realização dos objetivos da organização educacional (Leithwood e Earl). As tipologias vão tentar responder às questões analíticas fundamentais: "quem deve prestar contas", "a quem", "sobre o quê", "com que nível de prestação de contas (descrição, explicação, justificação)", "com quais consequências?”. Ao comparar a evolução das tipologias Maroy e Voisin (2013, p. 891) supõem

\begin{abstract}
que tais tipologias deixam de lado um ponto que nos parece essencial na análise da mudança das políticas de regulação por resultados. Os princípios de legitimidade ou as relações de prestação de contas ("quem deve prestar contas a quem") não são as realidades que mais se transformam. São, sobretudo, as ferramentas de ação pública que mudam, justificadas pelos princípios de legitimação e pelo quadro normativo que nos parece parcialmente inalterado. Em outras palavras, as mudanças das políticas seriam mais bem aproveitadas por meio das "ferramentas", de sua operacionalização, do que por meio dos princípios normativos ou das filosofias políticas que as justificam. Os atores que são levados a prestar contas e aqueles a quem se deve prestar contas não mudam significativamente; são principalmente os objetos e as consequências associadas à prestação de contas que evoluem, especialmente em razão de uma mudança de ferramentas.
\end{abstract}

$\mathrm{Na}$ evolução das políticas de accountability, não há muitas mudanças quando se analisa os atores que pedem a prestação de contas, assim como aqueles que devem prestar contas, “o que muda é o ‘como' e 'sobre o quê" (MAROY; VOISIN, 2013, p. 891). Assim, as avaliações externas, consideradas ferramentas importantes, vão sendo cada vez mais utilizadas para regular os comportamentos dos sujeitos envolvidos com a educação escolar.

Esse aumento da avaliação caminha junto com uma maior explicitação dos padrões curriculares e de desempenho que devem (ao menos teoricamente) sustentar as avaliações. Evidentemente falta ainda ver até que ponto tal "alinhamento" dos padrões é uma meta e se ele é bem feito na prática. (MAROY; VOISIN, 2013, p. 895).

Por outro lado, as consequências mudam dependendo do tipo de accountability (dura ou suave) e vão ser significativamente mais importantes porque mudam o significado das políticas atuais.

Com uma abordagem gerencialista e neoliberal, a produção da Labei (2006) aparece como uma grande defensora do que eles intitulam sistema de prestação de contas. O ponto central do texto é o pressuposto de que o sistema de prestação de contas por si só ajuda na melhoria da educação. Tal abordagem não considera 
o contexto sociopolítico em que está inserida a escola e seus sujeitos, nem se preocupa com o background dos estudantes. Esse documento defende que padrões, informações, consequências e autoridade constituem as quatro condições necessárias para a constituição de um bom sistema de prestação de contas.

Padrões devem ser definidos para estudantes, professores e para o material pedagógico. Informações devem ser coletadas sistematicamente, preferencialmente por meio da aplicação de provas para estudantes e professores, e devem ser divulgadas periodicamente. As consequências devem atingir professores e outros responsáveis pelo andamento da escola: diretores, supervisores, coordenadores, entre outros. Autoridade deve estar de acordo com a função que o sujeito/instituição exerce no desenvolvimento do sistema educativo. Deve haver autoridade da escola sobre os professores e sobre os recursos a serem utilizados. Os professores devem ter autonomia pedagógica e os pais devem ter autoridade para escolher a escola para seus filhos (há inclusive uma defesa do sistema de voucher ${ }^{2}$. Aqui é importante destacar que a pretensa autonomia pedagógica proposta por essa perspectiva estará sempre atrelada aos padrões de eficiência e eficácia exigidos para a escola, entendida como uma empresa.

Complementando esse debate, McMeekin (2006) defende, junto com Labei (2006), um modelo de accountability baseado nas quatro condições anteriormente referenciadas (padrões, informações, consequências e autoridade), mas acrescenta duas condições: desenvolvimento de capacidades (dos professores e diretores escolares), para cumprir os padrões, e explicação clara e persuasiva do conceito de accountability. Essas duas últimas condições atravessam o processo de desenvolvimento das outras quatro condições, seria algo transversal ao processo. Ou seja, para ter sucesso, não basta apenas implantar um "sistema de prestação de contas", é preciso construir condições para que os envolvidos compreendam e acreditem nos efeitos (positivos) do sistema para a melhoria da educação.

Es necesario emplear un tipo de "marketing social" y "vender" la idea de accountability a aquellos que será objeto de la misma. Hay dos razones para ello: (1) reduce la oposición al establecimiento de la accountability al dejar en claro que su fin es constructivo, y (2) ayuda a informar y persuadir a los maestros respecto de su papel en el mejoramiento de la educación. Los maestros son centrales al proceso educativo y necesitan aceptar el desafío de mejorar su próprio desempeño. (MCMEEKIN, 2006, p. 42-43). 2 O voucher educacional consiste, geralmente, na retirada de dinheiro da educação pública para dá-los a
famílias que desejam enviar seus filhos para escolas privadas (KLEES; EDWARDS JR, 2015). 
Como se pode ver na proposta acima, o tratamento dado à escola se dá com base na competição, na determinação de padrões, na imputação de sanções, porque são ações consideradas decisivas na eficiência educacional. O que se observa é que há nesse processo de controle uma supervalorização da racionalidade instrumental e de resultados quantificáveis, que, em vez de garantir a efetiva autonomia das instituições educacionais, acaba por responsabilizar os agentes educacionais pelo fracasso ou sucesso dos estudantes, estabelecidos em forma de números e padrões.

Afonso $(2009,2010,2012,2018)$ vem nos alertando sobre a necessidade de clarificar o termo accountability, e considera um equívoco o uso da expressão "políticas de responsabilização" como sinônimo de accountability.

O autor sugere a necessidade de fortalecer o debate teórico para avançar na discussão sobre accountability no sentido de um resgate crítico da sua problemática. “Torna-se necessário, por isso, mostrar que há outras alternativas que podem e devem ser reflexivamente consideradas e postas em prática, sobretudo por terem maior densidade teórico-conceptual e/ou pertinência política e educacional" (AFONSO, 2012, p. 477). Para tanto, se apoia, em princípio, em Stobart (2010 apud AFONSO, 2012, p. 477), que propõe:

[...] o que designa de "accountability inteligente". Trata-se de uma forma de prestação de contas e de responsabilização fundamentada em valores, promotora de confiança nos professores e nas escolas, mais construtiva do que a dos modelos atuais (cuja dominância é negativamente sancionatória), e que se baseia não exclusivamente em exames externos, mas em procedimentos e instrumentos de avaliação múltiplos, mais sofisticados e diversificados. Além disso, os objetivos ou metas educacionais a atingir deverão ser mais realistas, evitando a ambição pragmática e imediatista dos governantes que, frequentemente, os impõem desconsiderando ou desconhecendo condições, tempos, possibilidades, constrangimentos, recursos materiais, escolas, professores e comunidades educativas efetivamente existentes.

Esse autor segue afirmando que o termo accountability condensa diferentes dimensões ou pilares, de modo que para entender a sua essência é necessário estudar as articulações entre tais dimensões ou pilares e sua aplicação ao campo da educação.

Para explicar o conceito, Afonso (2009) toma as três dimensões estruturantes da accountability apontadas por Schedler (1999 apud AFONSO, 2009) - de informação, de justificação e de imposição ou sanção - e, a partir disso, define os pilares em um quadro que condensa as ideias a partir dos pilares da accountability, definidos em três: o pilar da prestação de contas, o pilar da responsabilização e o pilar da avaliação. Como isso pode ser explicado? O autor toma as três dimensões estruturantes da accountability apontadas por Schedler (1999 apud AFONSO, 2009) 
- uma de informação, outra de justificação e uma outra de imposição ou sanção - e, a partir disso, define os pilares acima citados.

Num entendimento mais imediato, a prestação de contas pode ser o pilar que sustenta ou condensa as duas primeiras: o direito de pedir informações e de exigir justificações — sendo que, para a concre $\neg$ tização de ambas, é socialmente esperado que haja a obrigação ou o dever (regulamentados legalmente ou não) de atender ao que é solicitado. Informar e justificar constituem assim duas dimensões da pres $\neg$ tação de contas, a qual pode, assim, ser definida, em sentido restrito, como obrigação ou dever de responder a indagações ou solicitações (answerability). (AFONSO, 2009, p. 59)

O autor ainda destaca que a prestação de contas, constituída por uma dimensão informativa e uma dimensão argumentativa, pode "[...] num certo sentido, ser concebida como uma actividade comunicativa ou discursiva porque pressupõe uma relação de diálogo crítico e a possibilidade de desenvolver um debate público aprofundado" (AFONSO, 2009, p. 59). Contudo, a concepção de prestação de contas, assume uma feição, além da “[...] obrigação ou dever de dar resposta (answerability) ${ }^{3}$, não é apenas uma actividade discursiva, mais ou menos benévola, que se esgota na informação e na justificação; ela contém também uma dimensão impositiva, coactiva ou sancionatória (enforcement)" (AFONSO, 2009, p. 59), denominada, pelo autor, de pilar da responsabilização.

[...] o pilar da responsabilização (em Schedler "enforcement") sintetiza outras dimensões: não apenas a que se refere à imputação de responsabilidades e à imposição de sanções negativas, mas também as que, em meu entender, podem ser acrescentadas — por exemplo, a assunção autônoma de responsabilidades pelos actos praticados; a persuasão; o reconhecimento informal do mérito; a avocação de normas de códigos deontológicos; a atribuição de recompensas materiais ou simbólicas, ou outras formas legítimas de (indução de) responsabilização. (AFONSO, 2009, p. 59).

Por fim, buscando ampliar a capacidade heurística de um modelo de accountability, o autor acrescenta o pilar da avaliação, que se refere ao processo de levantamento e tratamento de dados diversos, no sentido de produzir um juízo de valor sobre a situação. A avaliação pode anteceder a prestação de contas (avaliação ex ante), pode ocorrer posteriormente, entre a fase de prestação de contas e a fase de responsabilização (avaliação expost), ou ainda pode "ela própria, desenvolver se autonomamente através de estudos ou relatórios elaborados por entidades internas

3 “A expressão answerability poder se á tradu $\neg$ zir em português por respondabilidade, havendo, no entanto, 'quem refira o conceito de 'responsividade' que consiste na explicação motivada dos fatos per-quiridos. [...] Ser responsivo significa responder às questões formuladas, prestar esclarecimentos””. (MOTA, 2006, p. 57, apud AFONSO, 2009, p. 67) 
e/ou externas, assumindo se as $\neg$ sim como instrumento estruturante da prestação de contas (integrável ou não num modelo ou sistema mais amplo de accountability)" (AFONSO, 2009, p. 60). Ao analisar exemplos da política educacional, o autor toma essas dimensões e propõe a seguinte classificação para as práticas de política com elementos de accountability: formas parcelares de accountability, modelo de accountability e sistema de accountability, que sistematizamos no Quadro 1:

\section{Quadro 1 - Modelos emergentes de accountability}

\begin{tabular}{|c|c|c|}
\hline \multirow{3}{*}{$\begin{array}{c}\text { MODELOS DE } \\
\text { ACCOUNTABILITY }\end{array}$} & $\begin{array}{l}\text { formas parcelares de } \\
\text { accountability }\end{array}$ & $\begin{array}{l}\text { Aquelas acções ou procedimentos que dizem respeito apenas a algumas } \\
\text { dimensões da prestação de contas ou da responsabilização ("actos de } \\
\text { accountability" na linguagem de Schedler), não constituindo, por isso, um } \\
\text { modelo ou uma estrutura integrada }\end{array}$ \\
\hline & mo $\urcorner$ delo de accountability & $\begin{array}{l}\text { Uma estrutura mais comple } า x a \text {, preferencialmente adaptável, aberta } \\
\text { e dinâmica, em que diferentes dimensões ou formas parcelares de } \\
\text { accountability apresentam relações e intersecções congruentes, fazendo } \\
\text { sentido como um todo }\end{array}$ \\
\hline & sistema de accountability & $\begin{array}{l}\text { Um conjunto articulado de modelos e de formas par-celares de } \\
\text { accountability que, apresentando espe-cificidades e podendo manter } \\
\text { diferentes graus de autonomia relativa, constituem uma estrutura } \\
\text { con-gruente no quadro de políticas (públicas ou de inte-resse público) } \\
\text { fundadas em valores e princípios do bem-comum, democraticidade, } \\
\text { participação, dever de informar e direito a ser informado, argumentação } \\
\text { e contraditório, transparência, responsabilização, ci-dadania activa, } \\
\text { empowerment, entre outros. }\end{array}$ \\
\hline
\end{tabular}

Fonte: Elaboração própria, a partir de Afonso (2009).

Ao analisar diferentes experiências de políticas que envolvem avaliação externa, Afonso (2009) ressalta que há evidências suficientes que esteja em andamento uma constru-ção de "modelos e sistemas de accountability em educação, dado predominarem, em praticamente todos os casos, as dimensões referentes ao pilar da prestação pública de contas, isto é, as dimensões da justificação e da argumentação e, sobretudo, da informação" (AFONSO, 2009, p. 66).

Além disso, Afonso (2012, p. 480) destaca que a responsabilização, como um dos três pilares da configuração de accountability, assume a "conotação negativa e culposa em termos discursivos e de representação social”. As análises e debates sobre políticas de accountability educacional comumente têm sido realizados a partir dessa representação negativa da responsabilização. Ou seja, "a responsabilização é mais facilmente reduzida à ameaça ou imputação negativa de culpa sobre determinadas ações e seus supostos resultados" (AFONSO, 2012, p. 480).

Por outra parte, esse autor faz uma argumentação que põe em interação a avaliação, a prestação de contas e a responsabilização implicadas no processo de accountabilty. 
Numa sociedade democrática, para se poder prestar contas deve avaliar-se de forma fundamentada e o mais possível objetiva; e presta-se contas para procurar garantir a transparência e o direito à informação em relação à prossecução de políticas, orientações, processos e práticas. E se por alguma razão não for esperada nem for oportuna a assunção voluntária de eventuais responsabilidades pessoais, políticas ou institucionais, ou se, em decorrência da prestação de contas, houver lugar a prêmios ou sanções, ou outras formas de responsabilização de instituições, organizações ou pessoas, isso deve, ainda assim, ter em conta, consoante a especificidade dos casos, uma avaliação rigorosa e prudente sob o ponto de vista técnico-metodológico (tendo por referência não apenas critérios, objetivos e padrões previamente definidos, mas também processos amplamente participados e formativos), e tendo em conta igualmente o enquadramento cultural, ético e jurídico que preveja procedimentos democráticos e salvaguarde direitos fundamentais. (AFONSO, 2010, p. 153)

Por fim, entendemos que os estudos aqui destacados consistem numa pequena amostra do rico debate que envolve a accountability educacional e sua expressão nas políticas em ação neste momento no cenário brasileiro. O que reforça a necessidade de continuarmos estudando a área, especialmente tomando como referência o contexto atual, marcado pela adoção de estratégias gerencialistas de cunho neoliberal no que diz respeito às políticas para educação pública.

\section{CONSIDERAÇÕES FINAIS}

Como se pode ver, há diferentes entendimentos sobre accountability educacional. No entanto, é possível observar que a tríade avaliação, responsabilização e prestação de contas vai sendo utilizada como elemento de análise, para ir além do entendimento superficial que toma responsabilização como sinônimo de accountability. Aliados a essa tríade, outros elementos aparecem: exigência por informações, uso dos dados, autoridade, consequências; mas não aparecem com o mesmo grau de importância no interior desse rico debate. A abordagem de viés neoliberal defende a necessidade do uso desses elementos e, como tal, informam que eles são imprescindíveis para efetivação de uma educação de qualidade, entendendo que a qualidade deve ser 'medida' a partir de resultados (quantitativos). Por outra parte, é possível observar que há outra abordagem que aporta seus pressupostos em uma perspectiva democrática, evidenciando que a avaliação, por exemplo, pode estar ancorada em processos participativos e formativos, e não apenas em padrões previamente definidos.

Os processos que envolvem a aplicação de avaliação estandardizada e outras formas de padronização dos processos de gestão pedagógica das nossas escolas estão ligados a um modo de conceber a sociedade que se pauta na racionalidade neoliberal, cuja "característica principal [é] a generalização 
da concorrência como norma de conduta e da empresa como modelo de subjetivação" (DARDOT; LAVAL, 2016, p. 17). Uma das normas de conduta, então, é a competição generalizada. Esse movimento tem sido exposto pelas diversas pesquisas que vêm analisando os impactos das políticas de accountability educacional no interior dos sistemas estaduais de ensino: é preciso não só atingir as metas, mas ultrapassá-las e é necessário divulgar e premiar as escolas (vistas como empresas) que conseguirem atingir esse feito (SANTOS; ANDRADE; MARQUES, 2019). A gestão escolar e os professores estão sendo submetidos a novas formas de subjetivação, que tendem a excluir ou colocar em segundo plano o verdadeiro sentido da escola e da educação públicas.

Citando Boyer (1990, p. 80), podemos dizer que o modo de regulação de tais políticas conta com o conjunto dos procedimentos e de comportamentos, individuais ou coletivos, que visa a "reproduzir as relações sociais fundamentais através da conjunção de formas institucionais historicamente determinadas; sustentar e pilotar o regime de acumulação em vigor", baseando-se em processos de meritocracia e produtividade, que são elementos fundamentais para a manutenção do modelo capitalista neoliberal de sociedade em franca reprodução atualmente.

Assim, entendemos que a accountability educacional e especialmente as ações que envolvem a aplicação de avaliações externas devem ser analisadas no âmbito de teorias que nos ajudem a avançar nessa reflexão e sair do lugar comum. A regulação deve ser vista como um elemento necessário às políticas, mas o modo como as formas de regulação da educação têm sido implementadas aqui no país merece ser foco específico de uma análise estruturada, inclusive chamando a atenção para o que Souza e Oliveira (2003, p. 875) já nos alertaram ao caracterizarem a avaliação como "peça central nos mecanismos de controle, que se deslocam dos processos para os produtos, transferindo-se o mecanismo de controle das estruturas intermediárias para a ponta".

Afinal, é patente que estamos vivendo a consolidação de uma política nacional de avaliação que se estende sistematicamente pelos estados subnacionais, fortalecendo a figura do Estado regulador e avaliador, através da aplicação de testes padronizados para todos os níveis de ensino, e instituindo mecanismos de controle de resultados. Assim, essa política fomenta uma cultura de competitividade e concorrência entre os diversos elementos que compõem nossos sistemas escolares (professores, gestores, escolas...). 


\section{REFERÊNCIAS}

ADRIÃO, T.; GARCIA, T. Oferta educativa e responsabilização no PDE: o plano de ações articuladas. Cadernos de Pesquisa, v. 38, n. 135, p. 779-796, set./dez. 2008.

AFONSO, A. J. Gestão, autonomia e accountability na escola pública portuguesa: breve diacronia. Revista Brasileira de Política e Administração da Educação, [s. 1.], v. 26, n. 1, p. 13-30, jan./abr. 2010.

AFONSO, A. J. Para uma conceitualização alternativa de accountability em educação. Educação \& Sociedade, Campinas, v. 33, n. 119, p. 471-484, 2012.

AFONSO, A. J. Políticas avaliativas e accountability em educação: subsídios para um debate iberoamericano. Sísifo - Revista de Ciências da Educação, n. 9, p. 57-70, maio/ago. 2009.

AFONSO, A. J. Políticas de responsabilização: equívocos semânticos ou ambiguidades político-ideológicas? Revista de educação, PUC-Campinas, Campinas, 23(1):8-18, jan./abr. 2018. http://seer.sis.puc-campinas.edu.br/seer/ index.php/reveducacao/article/view/4052/2563. Acesso em 02/2019.

AZEVEDO, J. M. L.; GOMES, A. M. Intervenção e Regulação: contribuição ao debate no campo da educação. Linhas Críticas, Brasília, v. 15, n. 28, p. 95-107, jan./jun. 2009.

BOYER, R. A teoria da regulação: uma análise crítica. Tradução de Renée Barata Zicman. São Paulo: Nobel, 1990.

BROOKE, N. Sobre a equidade e outros impactos dos incentivos monetários para professores. Estudos em Avaliação Educacional, São Paulo, v. 24, n. 55, p. 34-62, abr./ago. 2013.

BROOKE, N. O futuro das políticas de responsabilização educacional no Brasil. Cadernos de Pesquisa, v. 36, n. 128, p. 377-401, maio/ago. 2006. 
CUNHA, C. P. Prática Docente Sob Pressão: Ações e percepções de professores sobre a política de responsabilização na rede municipal de ensino do Rio de Janeiro. Dissertação (Mestrado em Educação) - Universidade Federal do Rio de Janeiro, Rio de Janeiro, 2015.

DARDOT, P.; LAVAL, C. A nova razão do mundo: ensaio sobre a sociedade neoliberal. São Paulo: Editora Boitempo, 2016.

FURTADO, C. S. V. Responsabilização Educacional em Pernambuco. 249 f. Tese (Doutorado em Educação) - Universidade Federal de Juiz de Fora, Juiz de Fora, 2015.

KLEES, S. J.; EDWARDS JR., D. B. Privatização da educação experiências dos Estados Unidos e outros países. Revista Brasileira de Educação, v. 20 n. 60, jan./mar. 2015. https://www.scielo.br/pdf/rbedu/v20n60/1413-2478rbedu-20-60-0011.pdf. Acesso em 03/2020.

LABEI. Documento del Latin American Basic Education Initiative (LABEI, 2001). Cumbre Latinoamericana de Educación Básica (Sección II, pp. 12-14). In: CORVALÁN, J.; MCMEEKIN, R. W. (Edit.) Accountability educacional: posibilidades y desafíos para América Latina a partir de la experiencia internacional. Santiago do Chile: Cide-PREAL, 2006.

LINDOSO, R. C. B.; SANTOS, A. L. F. Política educacional e a avaliação em larga escala como elemento de regulação da educação. Jornal de Políticas Educacionais, v. 13, n. 1, jan. 2019. https://revistas.ufpr.br/jpe/article/ view/61241. Acesso em 05/2019.

MACHADO, C. et al. Sistemas estaduais de avaliação: interfaces com qualidade e gestão da educação. Revista Brasileira de Política e Administração da Educação, v. 31, n. 3, p. 667- 680, set./dez. 2015. https://www.seer.ufrgs.br/ $\mathrm{rbpae} /$ article/view/63800/37029. Acesso em 02/2020.

MCMEEKIN, R.W. Hacia una comprensión de la accountability educativa y cómo puede aplicarse en los países de América Latina. In: CORVALÁN, J.; MCMEEKIN, R. W. (Edit.) Accountability educacional: posibilidades y desafíos para América Latina a partir de la experiencia internacional. Santiago do Chile: Cide-PREAL, 2006. 
MAROY, C.; VOISIN, A. As transformações recentes das políticas de accountability na educação: desafios e incidências das ferramentas de ação pública. Educação \& Sociedade, v. 34, n. 124, p. 881-901, jul./set. 2013.

NOGUEIRA, R. S. Avaliação em larga escala como regulação: o caso do Sistema Estadual de Avaliação da Aprendizagem Escolar - Seape/Acre. Tese (Doutorado em Educação) - Universidade Federal do Paraná, Curitiba, 2015.

OLIVEIRA, M. A. A. Discursos em circulação sobre políticas de avaliação e accountability na educação básica: estados da região nordeste em foco. Tese (Doutorado em Educação) -Universidade Federal de Pernambuco, Programa de Pós-Graduação em Educação, Recife, 2019.

PERBONI, F. Avaliações externas e em larga escala nas redes de educação básica dos estados brasileiros. Tese (Doutorado em Educação) - Universidade Estadual Paulista, Faculdade de Ciências e Tecnologia, Presidente Prudente, 2016.

SANTOS, A. L. F; ANDRADE, E. F.; MARQUES, L. R. (Org.) Políticas educacionais no estado de Pernambuco: discursos, tensões e contradições. 1. Ed. Recife: Editora UFPE, 2019, v. 1, p. 115-139.

SCHNEIDER, M. P. Tessituras intergovernamentais das políticas de accountability educacional. Revista Educação em Questão, Natal, v. 55, n. 43, p. 162-186, jan./ mar. 2017. https://periodicos.ufrn.br/educacaoemquestao/article/view/11811. Acesso em 02/2019.

SILVA, A. F. Políticas de accountability na Educação Básica brasileira: um estudo do pagamento de docentes por desempenho. Revista Brasileira de Política e Administração da Educação, v. 32, n. 2, p. 509-526, mai./ago. 2016. https:// www.seer.ufrgs.br/rbpae/article/view/59520/38378. Acesso em 11/2029.

SILVA, K. N. P.; SILVA, J. A. A. Accountability e intensificação do trabalho docente no Ensino Médio Integral de Pernambuco. Práxis Educativa, Ponta Grossa, v. 9 , n. 1, p. 117-140, jan./jun. 2014.

SOUZA, S. M. Z. L.; OLIVEIRA, R. P. Sistemas estaduais de avaliação: uso dos resultados, implicações e tendências. Cadernos de Pesquisa, v.40, n.141, set./dez. 2010. https://www.scielo.br/scielo.php?pid=S0100$15742010000300007 \&$ script=sci_abstract\&tlng=pt. Acesso em 03/2020. 


\section{Ana Lúcia Felix Santos}

Doutora em Educação pela UFPE. Professora Associada do Departamento de Psicologia e Orientação Educacionais do Centro de Educação/UFPE. Professora do Programa de Pós-Graduação em Educação/CE/UFPE.

E-mail: analufelix@gmail.com

\section{Emília Vilarinho}

Doutora em Ciências da Educação pela Universidade do Minho, Portugal. Professora assistente do Instituto de Educação da Universidade do Minho. E-mail: evilarinho@ie.uminho.pt

Recebido em 30/06/2020

Aprovado em 10/08/2020 